\title{
ENERGY STUDY OF A GREENHOUSE AND OPTIMISATION OF THE CHOICE OF SHAPE AND COVERING MATERIAL: BASED ON AN IMPROVED STATIC MODEL
}

\author{
Anouar Belkadi ${ }^{*}$, Dhafer Mezghani ${ }^{1}$, Abdelkader Mami1 \\ ${ }^{1 *}$ Corresponding author. Faculty of Sciences of Tunis, University of Tunis El Manar/ Tunis, Tunisia. \\ Email: belkadi.anouar@gmail.com | ORCID ID: https://orcid.org/0000-0001-9634-1771
}

\section{KEYWORDS}

cooling, daylight, greenhouse design, heating, energy

consumption.

\begin{abstract}
This paper presents a new approach to properly estimate energy consumption inside a greenhouse. In this study, we have adopted improved classical modelling to evaluate the energy balance of a greenhouse with a higher precision. While the traditional classical model focuses mainly on the cooling and heating (and denies the deep influence of lighting factors), we demonstrate the importance of considering these three necessary components as being interdependent through this academic study; they should all be integrated in order to reach optimal crop production and efficient energy consumption. Our contribution will be to improve the traditional classical model and to demonstrate that daylight, as well as artificial lighting, has fundamental consequences on the estimating of the required energy consumption and the choice of the optimal shape and coverage material of the greenhouse.
\end{abstract}

\section{INTRODUCTION}

Nowadays, energy consumption is becoming the most important factor in the world (Zhu \& Li, 2015. The reserves of non-renewable energy resources have recently been found to be lower than expected, which is very worrying, and these resources have a negative impact on the greenhouse effect and on climate change. (Chen \& Chen, 2011). Due to this fact, Scientific developments are moving towards the use of renewable energies are migrating to the use of renewable energy (e.g., solar energy) which could be used either in a direct or indirect way by converting its energy into another type of energy. For example, solar energy can be used for illumination, cooling and heating. This approach has reached many sectors (such as industry, healthcare and education) but it is mostly used in agriculture, particularly for greenhouses (Khattar et al., 2019; Adeli et al., 2020; Ahemd et al., 2016).

In Tunisia, the development of rural areas is based on agriculture, which employs more than $50 \%$ of the population (Atia \& El-Madany, 2016). However, for several years, this sector has experienced a significant decrease in responsiveness to the local and international market due to the lack of availability and productivity required to guarantee a good quality of agricultural products. In addition, the impact of climate and poor water resource management aggravates the lack of productivity and the quality of Tunisian products. On the other hand, the training programs are not well adapted to the real needs of the farmer and do not incorporate the notions of sustainable energy and smart control systems.

All of these factors inspired us to prepare this work, which presents part of a larger project, in which we aim to present a new approach for correctly optimising energy consumption in a greenhouse. In order to meet this need, the thermal model must be properly dimensioned and take into account the possible transfers that will take place in a greenhouse. At present, there are three thermal models: dynamic, intermediate and static.

The static model (Ge et al., 2016; IRENA 2015; Ma et al., 2019) is a model that allows the calculation of the capacity and power required by the heating and cooling equipment, by referring to a meteorological database. This model does not take the solar radiation into account.

The intermediate model (Fitz et al., 2010 ; Belkadi et al., 2019 ; Fan \& Hao, 2019 ; Abbaspour et al., 2019 ; Abbaspour et al., 2020 ; Abbaspour et al., 2019 ; Belkadi et al., 2019 ; Adedeji et al., 2017; Ahemd et al., 2016) is used often. It is not as accurate as the dynamic models but it remains an interesting model; it requires more work to make it more rigorous. This model takes into account the sunshine and all types of heat transfer.

\footnotetext{
${ }^{1}$ Faculty of Sciences of Tunis, University of Tunis El Manar/ Tunis, Tunisia.
} 
The dynamic model (Belkadi et al., 2020; Wei et al., 2019; Atalay et al., 2017; Aviara et al., 2017; Aktas et al., 2016; Noorollahi et al., 2016) is a model that has proved to be accurate and we can assume that it has reached its limits of contribution. It is a very complex model to manipulate since the modification of one or more inputs requires very complex modifications and configurations.

In our dimensioning, we have adopted the classical model but adhered to new approaches to improve the accuracy and reliability of the energy consumption in a greenhouse and to make the best choice, in terms of coverage and shape of the greenhouse.

\section{MATERIAL AND METHODS}

Our approach is mainly and essentially based on the work of previous classical models that take into account the different components that influence the heat balance in greenhouses in particular.
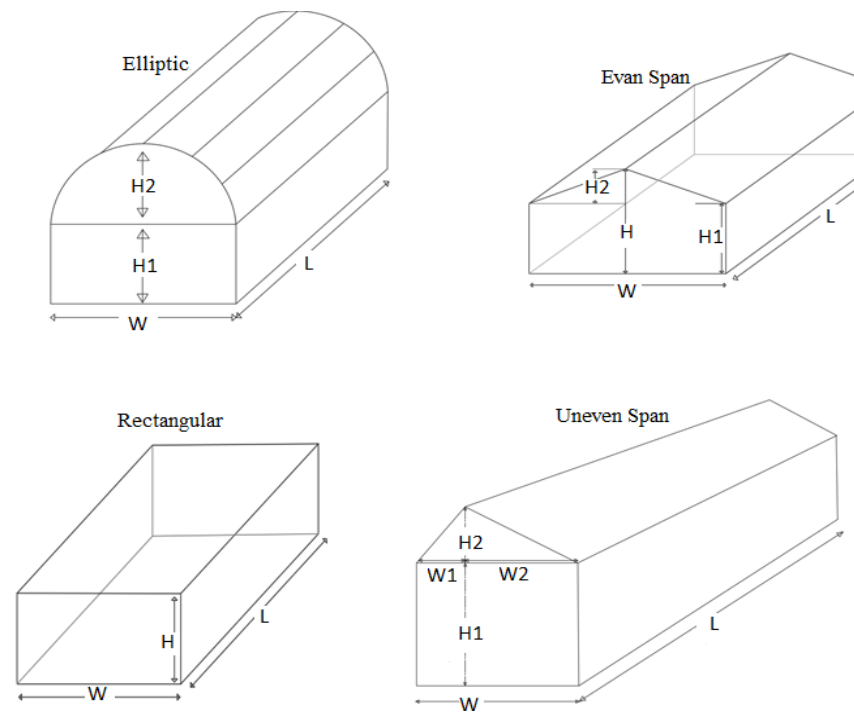

FIGURE 1. Analysed Greenhouse Forms.

Specifications of the greenhouse covering materials analysed

Five diverse greenhouse covering materials were considered in our study and their characteristics are listed in Table 1 [21-24].

TABLE 1. Characteristics of covering materials.

\begin{tabular}{cccccc}
\hline & GL & LEG & PE & PC & Acr \\
\hline Index & M1 & M2 & M3 & M4 & M5 \\
$\mathbf{L}_{\mathbf{c}}$ & $152.10^{-6}$ & $32.10^{-3}$ & $3.10^{-3}$ & 0.01 & $6.10^{-3}$ \\
$\mathbf{S}_{\text {tr }}$ & 0.87 & 0.78 & 0.905 & 0.9 & 0.9 \\
$\mathbf{L}_{\mathbf{w t}}$ & 50 & $<3$ & 3 & $<3$ & $<5$ \\
$\mathbf{K c}$ & 0.33 & 0.76 & 0.76 & 0.17 & 0.2 \\
$\mathbf{A C H}$ & 0.85 & 1.1 & 1.1 & 1.1 & 1.1 \\
\hline
\end{tabular}

\section{Study of heating needs of classical models}

The calculation of the heating requirements, according to the conventional models, is shown in eqs (1) and (2). It is based on the static heat loss coefficient $U_{\text {static }}$ given by the manufacturer (see Table 2), the surface of the greenhouse and the difference between the external temperature and the set point.
These theoretical models have paved the way for a more important contribution. According to the classical model, the calculation of the cooling and heating needs does not depend on solar radiation but only relies on meteorological data.

\section{Study of the conventional classical model}

\section{Choice of covering materials and shapes}

Throughout our analysis we focussed on the following forms and covering materials of greenhouses.

\section{Specifications of greenhouse forms analysed}

Four different shapes of greenhouses were analysed, as shown in Figure 1. The analysis of these greenhouses was carried out for the same volume $\left(4420 \mathrm{~m}^{3}\right)$ and dimension of the base surface ( $w=34 \mathrm{~m}, \mathrm{~L}=40 \mathrm{~m})$.

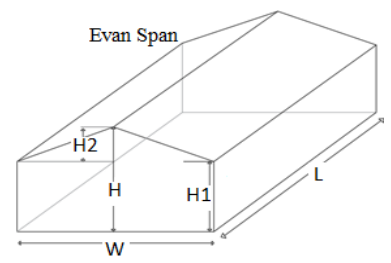

TABLE 2. Coefficient of static heat loss $U_{\text {Static. }}$

\begin{tabular}{|c|c|c|}
\hline & Cover materials & UStatic \\
\hline M1 & Glass (single layer) & 1.13 \\
\hline M2 & Low-emissivity glass & 0.45 \\
\hline M3 & Polyethylene & 1.20 \\
\hline M4 & Polycarbonate & 1.05 \\
\hline M5 & Acrylic & 1.13 \\
\hline & $H_{\text {mpn }}=A\left(T_{\text {in }}-T_{\min }\right) U_{\text {static }}$ & $(1$ \\
\hline
\end{tabular}

Equation (1) was used to size the heating equipment, in order to ensure proper operation in the worst-case weather scenario, while [eq. (2)] was used to determine the average heating requirement.

Figure 2 and Figure 3 show respectively the minimum and the average daily heating energy demand in $\mathrm{kWh} \mathrm{m}^{-2}$. 


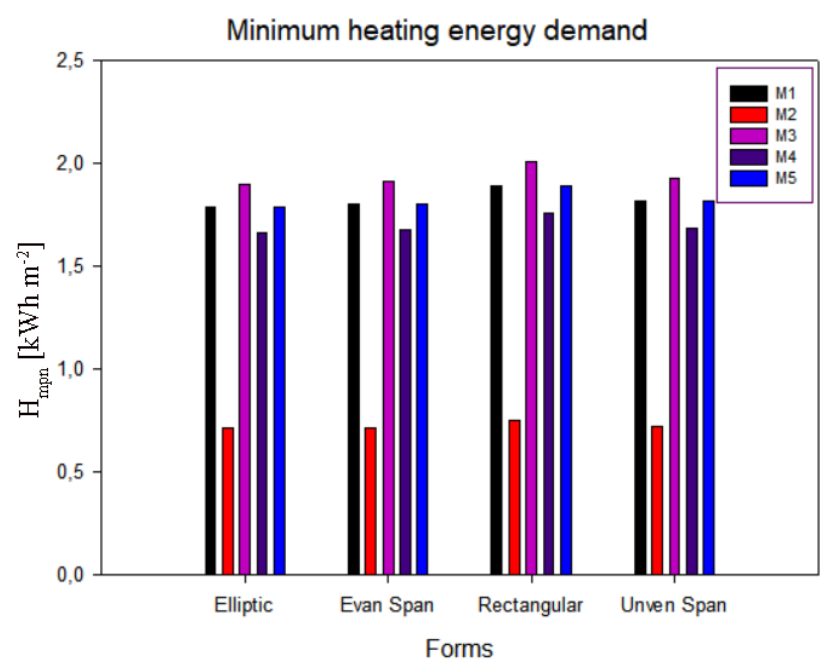

FIGURE 2. Minimum energy demand for heating of the traditional model $\left[\mathrm{kWh} \mathrm{m}^{-2}\right]$.

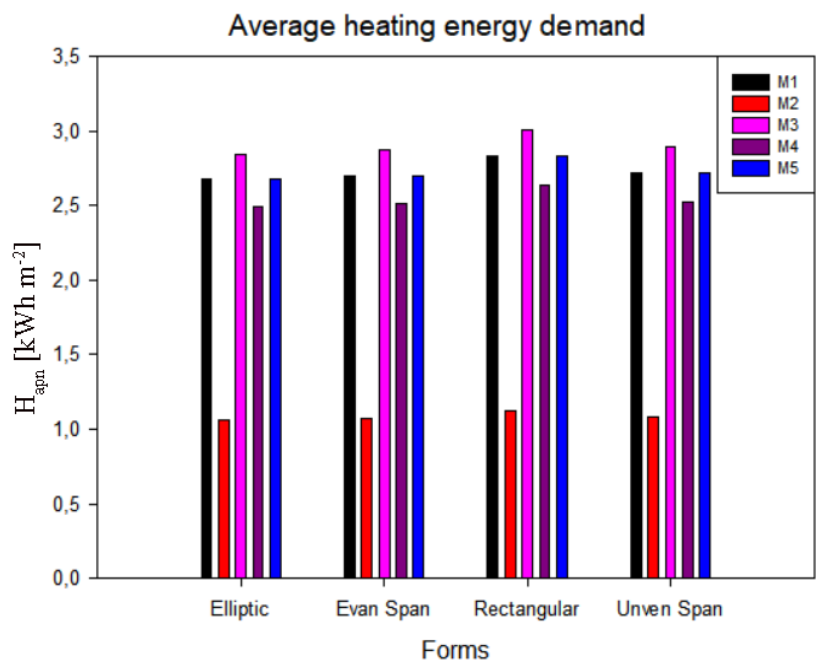

FIGURE 3. Average heating energy demand of the traditional model $\left[\mathrm{kWh} \mathrm{m}^{-2}\right]$.

From Figure 2 and Figure 3, we conclude that the covering material M2 consumed little energy. It consumed 1 $\frac{1}{3}$ materials. This result was expected, due to its low heat loss value.

Regarding the shape of the greenhouse, we deduced that the energy consumption was almost identical; it was difficult to distinguish the most economical shape.

\section{Study of cooling needs of classic models}

The estimation of the cooling system was based on the calculation of the optimal value of the exhaust fan (in $\mathrm{m}^{3} \mathrm{~s}^{-1}$ ), as shown in [eq. (3)].

$$
C_{a p n}=0.85 W L H
$$

A fan of this size will exchange the air in the greenhouse at least once per second, which is recommended for the ventilation of small greenhouses.

For large greenhouses, it was necessary to install an evaporative cooler, as represented in [eq. (4)] for greenhouses without shade cover and [eq. (5)] for greenhouses equipped with $50 \%$ or more shade cover.

$$
\begin{aligned}
& P_{\text {Cooler }}=2 C_{\text {apn }} \text { Eff } \\
& P_{\text {Cooler }}=C_{\text {apn }} E f f\left(1+\frac{1-S_{f}}{100}\right)
\end{aligned}
$$

Figure 4 shows the average daily cooling energy demand $\left[\mathrm{kWh} \mathrm{m}^{-2}\right]$. 


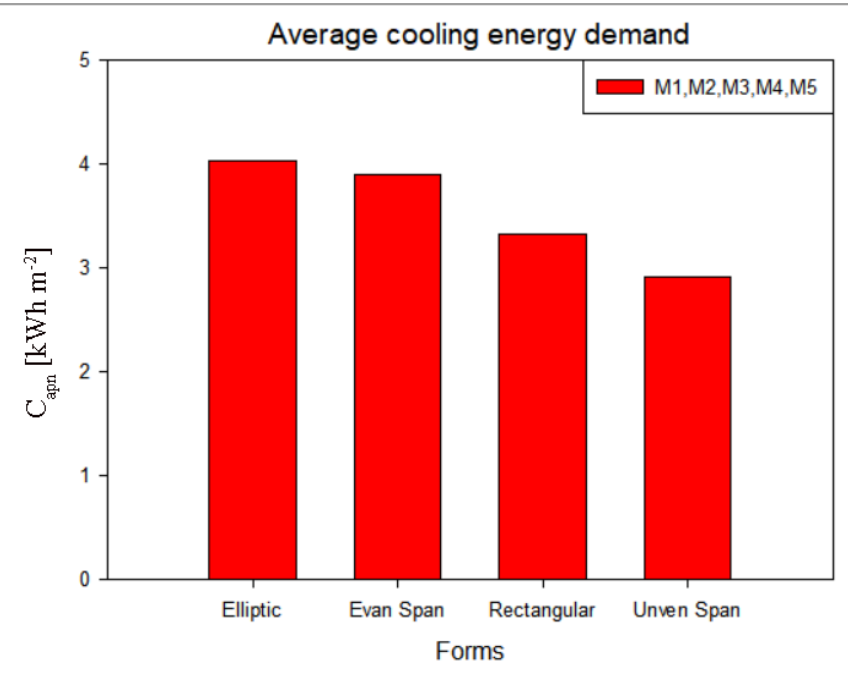

FIGURE 4. Average cooling energy demand of the traditional model $\left[\mathrm{kWh} \mathrm{m}^{-2}\right]$.

\section{Presentation of the BGHMC model}

Our implemented model, called 'BGHMC', was essentially inspired by the traditional classical model into which we injected new parameters.

- We recalculated the heating requirement by taking the global heat loss coefficient $U$ as a dynamic value, which was taken statically during the studies of the traditional models.

- We took into account some correction factors for the calculation of the cooling system, such as $\mathrm{F}_{\text {light }}, \mathrm{F}_{\text {elev }}, \mathrm{F}_{\mathrm{vel}}$ and $\mathrm{F}_{\text {temp. }}$.

- We improved the cooling system by using a PAD evaporative cooling system.

\section{Study of heating needs of the BGHMC model}

To determine the optimal required heating load, we needed to calculate the minimum power required, using [eq. (6)].

$$
H_{\text {mpn }}=A\left(T_{i n}-T_{\min }\right) U_{\text {dynamic }}
$$

$U_{\text {dynamic }}$ represents the heat loss of the material. In our model, this value represents a dynamic value, which is contrary to the traditional classical model where it is a static value. $T_{\min }$ represents the lowest temperature value, which allowed us to dimension the heating equipment to ensure proper operation in the worst-case weather scenario.

Figure 5 shows the minimum heating power required for each type of greenhouse and material used.

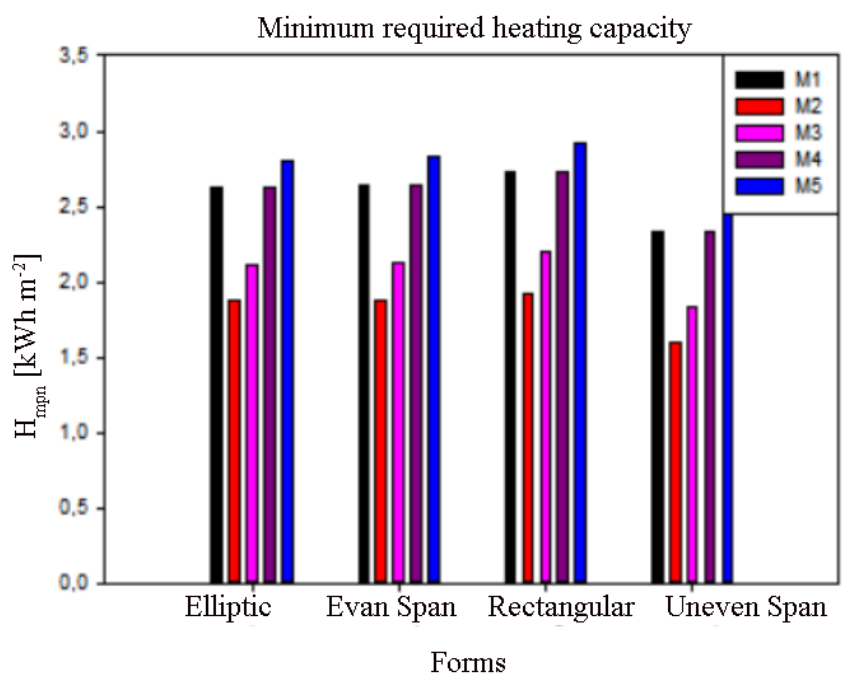

FIGURE 5. Minimum power required for heating $\left[\mathrm{kWh} \mathrm{m}^{-2}\right]$.

To estimate the average daily heating consumption, we need to determine the average low temperature, which is actually the sum of the minimum temperatures for each month divided by the number of months, and then calculate the average power required for each shape and each cladding of the greenhouse, using [eq. (7)].

$$
H_{\text {apn }}=A\left(T_{\text {in }}-T_{\text {av }}\right) U_{\text {dynamic }}
$$

Figure 6 shows the daily consumption of the heater for each type and material of the greenhouse. 


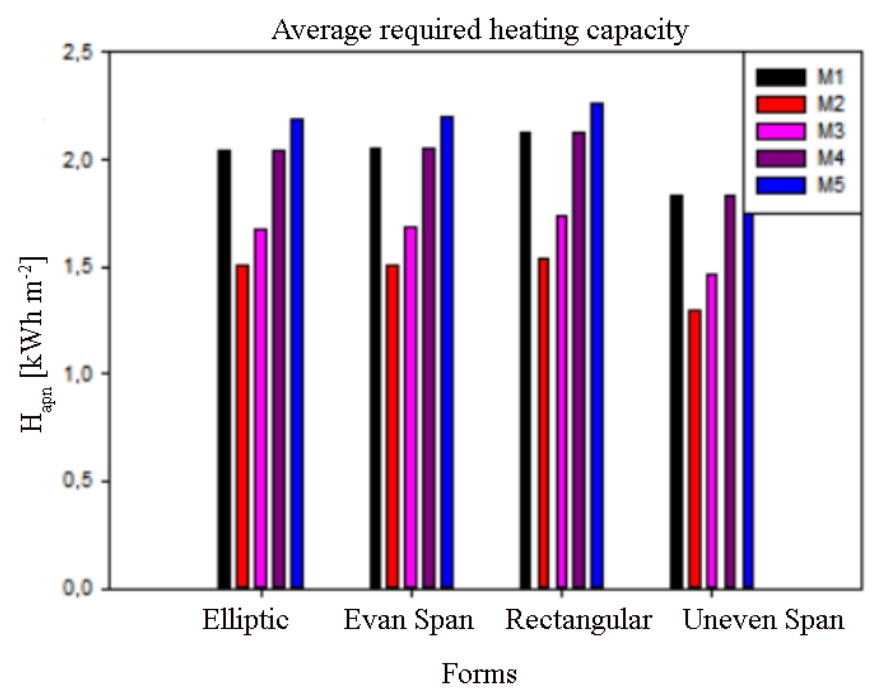

FIGURE 6. Average daily consumption of the heater $\left[\mathrm{kWh} \mathrm{m}^{-2}\right]$.

Figure 5 and Figure 6 clearly show that the coating material M02 has the lowest power requirement, which was expected due to its low heat loss value, while M05 had the highest power requirement. It is also remarkable that the most economical form was the Uneven span, while the rectangular shape was the most energy-consuming.

\section{Study of cooling needs of the BGHMC model}

Cooling is one of the most important components of a greenhouse. Its role is to provide fresh air and to cool the greenhouse. Poor ventilation in a greenhouse can damage plants and is similar to a solar cooker. The major problem with a greenhouse is that it is mainly designed to store the sun's heat during the day, which makes the cooling of a greenhouse on a hot day very complicated and can only be guaranteed by a good dimensioning of the cooling system.

The choice of cooling system depends on many parameters: altitude, climate, wind, size, etc. The cooling system can be natural, mechanical or cooling system such as PAD system.

\section{a) Natural ventilation}

Natural ventilation does not need electricity, it is created by the wind using a wind opener. The door opener is a kind of metal cylinder that contains a mineral which, once heated, expands to push a piston to open the door opener. It shrinks when the temperature gets colder. According to the American Society of Agricultural and Biological Engineers standards, the size of this opener should be at least 15 to $20 \%$ of the ground surface; this system is mostly used during the winter. Figure 7 shows a greenhouse with a natural ventilation system.

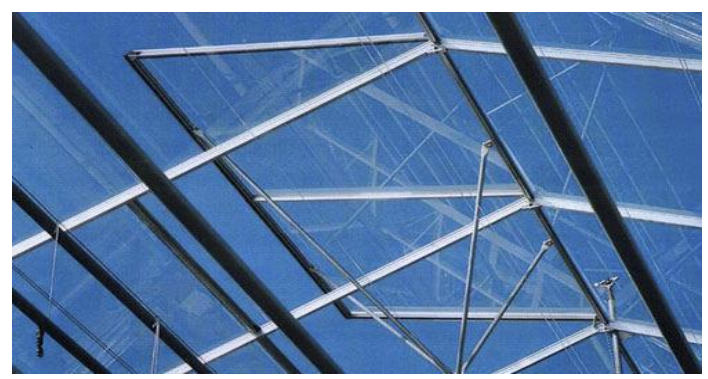

FIGURE 7. Natural ventilation of a greenhouse.

\section{b) Mechanical ventilation}

Mechanical ventilation is created by an electric fan and air extraction system, which can be either shutters or openings, but this system is not effective for summer ventilation as it is not able to maintain the desired greenhouse temperature in warm areas. Figure 8 shows a greenhouse with a mechanical ventilation system.

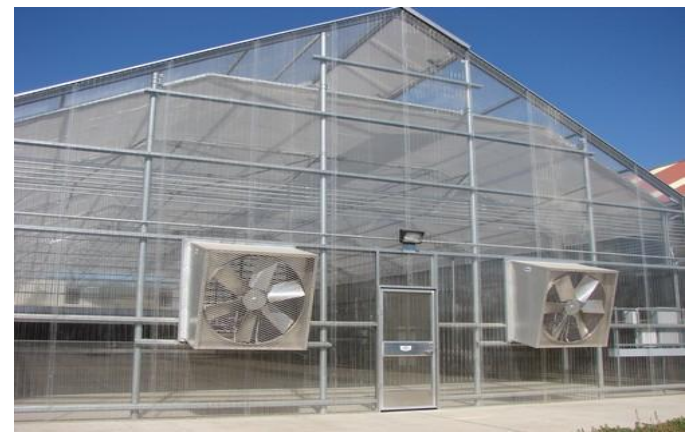

FIGURE 8. Mechanical ventilation of a greenhouse.

\section{c) Cooling System}

As Tunisia is a relatively warm region, the incoming air must be cooled by using an evaporative cooler to cool the outside wet tank between 16.66 and $15.55^{\circ} \mathrm{C}$ of the cooling system. For this reason, we had to use an evaporative cooling system, also known as PAD cooling system. Figure 9 shows the ventilation system used.

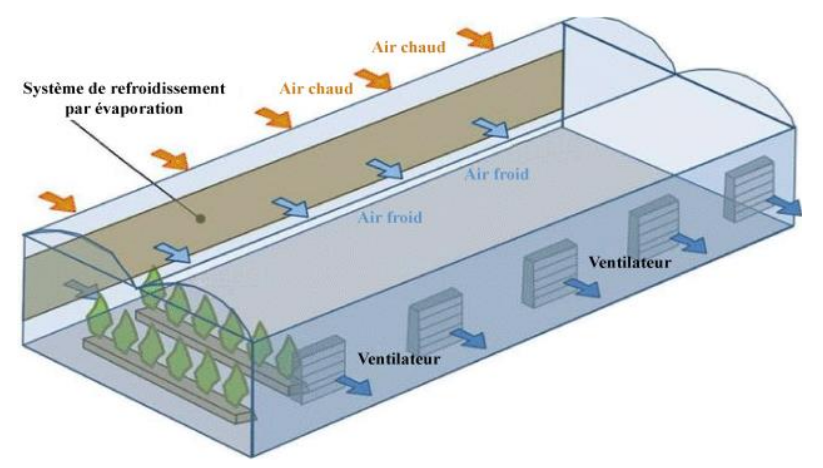

FIGURE 9. PAD cooling system. 
In order to estimate the load on the cooling system of a greenhouse, we calculated the total volume flow required and that of the evaporative panel system.

The required volumetric flow Dv for each square metre of the greenhouse was calculated using $4.0610^{-02} \mathrm{~m}^{3} \mathrm{~s}^{-1}$ for normal weather and $8.6310^{-02} \mathrm{~m}^{3} \mathrm{~s}^{-1}$ for a warm climate (Aktas et al., 2016; Atalay et al., 2017) respectively and then applying other relevant factors, such as $\mathrm{F}_{\text {light }}, \mathrm{F}_{\text {elev, }}, \mathrm{F}_{\mathrm{vel}}$ and $\mathrm{F}_{\text {temp. }}$.

\section{- F elev Factor}

The capacity of air to evacuate heat depends mainly on its weight and not on its volume. Since air is less dense as altitude increases and more air is needed to provide the equivalent weight compared to normal conditions, deviations from the standard can be compensated for by an elevation factor $F_{\text {Elev }}$.

This factor is estimated at 1 for altitudes below 304.8 $\mathrm{m}$, which is the case in Tunisia, otherwise it must be calculated using [eq. (8)]. Where BP is the local barometric pressure:

$$
F_{\text {Elev }}=\frac{29.92}{\text { BP }}
$$

\section{- $F_{\text {light }}$ Factor}

The interior light intensity, which depends on the location of the greenhouse, the amount of shade, and the intensity of daylight, determines the amount of heat brought to the greenhouse. This adjustment factor $F_{\text {Light }}$ is calculated using [eq. (9)].

$$
F_{\text {Light }}=\frac{L_{\max }}{5000}
$$

In our case, the value of $\mathrm{L}_{\max }$ relative to the rectangular shape equipped by M01 was evaluated to $16 \mathrm{Klux}$, as detailed in part of the simulation of the natural lighting of the greenhouse. This factor was estimated to be 0.25 .

\section{- $F_{\text {Temp }}$ Factor}

The greenhouse temperature increases from the pad to the fan $\left(\Delta \mathrm{T}_{\mathrm{p}-\mathrm{f}}\right)$, which is a very important design factor. It is inversely proportional to the airflow and can be adjusted to any value. If this value is different from $13.88^{\circ} \mathrm{C}$, the temperature increase factor $F_{\text {Temp }}$ is calculated using [eq. (10)].

$$
F_{\text {Temp }}=\frac{7.0}{\Delta T_{\mathrm{p}-\mathrm{f}}}
$$

The combination of all these factors determines the adjustment factor, which is used to complete the design capability of the cooling system.

$$
F_{\text {house }}=\mathrm{F}_{\mathrm{Temp}} F_{\text {Elev }} F_{\text {Light }}
$$

\section{- $F_{\text {vel }}$ Factor}

The transverse velocity of the air flow inside the greenhouse becomes too low and we often feel that the greenhouse is humid even if we ensure sufficient thermal balance. To avoid this and to increase the air velocity, we have to use a control factor which can be calculated using [eq. (12)].

$$
F_{v e l}=\frac{10}{\sqrt{D p-f}}
$$

After selection of the appropriate adjustment factors $F_{\text {house }}$ and $F_{\text {vel }}$, the total volume of air required for cooling a greenhouse is obtained by multiplying the floor area of the greenhouse by the base air flow rate and the appropriate adjustment factor, by applying [eq. (13)].

$$
T_{F}=D_{v} L w F_{\text {House }} F_{\text {vel }}
$$

We then determined the appropriate size and number of fans able to produce the required air volume and the surface area of the cooling panel, this included specifying the length and height of the pad system, the capacity of the water basin and related components.

The preferred distance between the pad and the fan, to obtain the best airflow speeds, ranged from 30 to $70 \mathrm{~m}$. For very long greenhouses, growers should plan to install a PAD at both ends with exhaust fans in the middle, using wall or roof-mounted fans. The cooled air then enters at each end and is exhausted in the middle of the greenhouse.

\section{a) Fan sizing}

A sufficient number of fans has been selected to provide the required amount of air, at a static pressure of 24.91 Pascal. A wind of $25 \mathrm{~km}$ per hour is approximately equal to 24.91 Pascal of static water pressure.

The number of fans required was determined by the size of the selected fans. the fans used are capable of providing a maximum spacing of $7 \mathrm{~m}$ along the exhaust side of the greenhouse.

\section{b) Sizing of cooling panels}

To determine the surface area of the cooling panel pad, it is recommended that the total air volume calculated in [eq. (14)] is divided by 150 , if the pads are made of aspen wood, as shown in Figure 10a. Whereas, if they are made of corrugated cellulose (Figure 10b), divide by 250 and 350 if their thickness is $10.16 \mathrm{~cm}$ or $15.24 \mathrm{~cm}$, respectively.

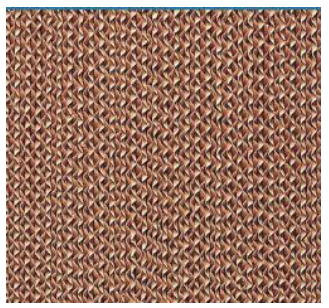

FIGURE 10a. Aspen wood.

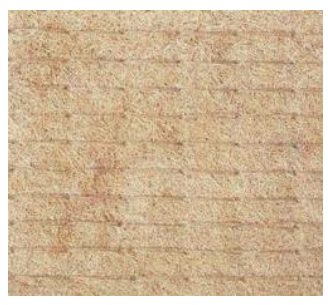

FIGURE 10b. Corrugated cellulose.

In the case studied, $16 \mathrm{~mm}$ corrugated cellulose was used, which lead us to determine the surface of the pad using [eq. (14)]. 


$$
P_{a}=\frac{T_{F}}{250}
$$

To determine the height of the pad, it was necessary to divide the area by the length, as shown in [eq. (15)].

$$
P_{h}=\frac{P_{a}}{l}
$$

It was then necessary to dimension the water tank and the necessary flow rate.

To determine the necessary water flow Pc, we used [eq. (16)].

$$
P_{c}=\mathrm{P}_{\mathrm{L}} G
$$

Where $\mathrm{G}$ is the required water flow rate in $\mathrm{m}^{3} \mathrm{~s}^{-1}$ per linear metre, it is estimated to be $2.110^{-5} \mathrm{~m}^{3} \mathrm{~s}^{-1}$ per linear meter for the aspen wood pad, and $3.1510^{-5} \mathrm{~m}^{3} \mathrm{~s}^{-1}$ and $4.7310^{-5} \mathrm{~m}^{3} \mathrm{~s}^{-1}$ per linear metre for the $10.16 \mathrm{~cm}$ and 15.24 $\mathrm{cm}$ thick corrugated cellulose pads, respectively (Aktas et al., 2016; Atalay et al., 2017).
To determine the capacity of the water reservoir, the capacity of the required settling tank G2 must be multiplied by the pad surface area, as shown in [eq. (17)].

$$
S_{t}=P_{\mathrm{a}} G_{2}
$$

G2 should be sized to provide $3.410^{-3} \mathrm{~m}^{3} \mathrm{~s}^{-1}$ for the aspen wood pad and $5.0910^{-3} \mathrm{~m}^{3} \mathrm{~s}^{-1}$ and $6.810^{-3} \mathrm{~m}^{3} \mathrm{~s}^{-1}$ for the cellulose pad of thicknesses $10.16 \mathrm{~cm}$ and $15.24 \mathrm{~cm}$, respectively.

All of the greenhouse types studied had the same floor area and design parameters, the only difference was in the $F_{\text {Light }}$ factor and this was due to the maximum illumination inside the greenhouse. These parameters were calculated according to the daylight simulation, discussed in the section: 'Study of lighting needs of classical models.

Table 3 shows the maximum illumination and the $F_{\text {Light }}$ factor for each type and cover material of the greenhouse.

TABLE 3. Maximum illumination and illumination factor.

\begin{tabular}{ccccccccc} 
& \multicolumn{2}{c}{ Elliptic } & \multicolumn{2}{c}{ Even span } & \multicolumn{2}{c}{ Rectangular } & \multicolumn{2}{c}{ Uneven span } \\
\cline { 2 - 8 } & $\boldsymbol{L} \boldsymbol{u} \boldsymbol{x}$ & $\boldsymbol{F}_{\text {light }}$ & Lux & $\boldsymbol{F}_{\text {light }}$ & $\boldsymbol{L u x}$ & $\boldsymbol{F}_{\text {light }}$ & Lux & $\boldsymbol{F}_{\text {light }}$ \\
\hline M 01 & 14918 & 32.1 & 14995 & 32.2 & 16104 & 34.6 & 15340 & 33.0 \\
M 02 & 12171 & 26.2 & 13548 & 29.1 & 14157 & 30.4 & 13893 & 29.9 \\
M 03 & 13248 & 28.5 & 14625 & 31.4 & 15234 & 32.8 & 14970 & 32.2 \\
M 04 & 13955 & 30.0 & 15332 & 33.0 & 15941 & 34.3 & 15677 & 33.7 \\
M 05 & 13955 & 30.0 & 15332 & 33.0 & 15941 & 34.3 & 15677 & 33.7 \\
\hline
\end{tabular}

Figure 11 shows the annual cooling energy consumption for each type and cover material of the greenhouse.

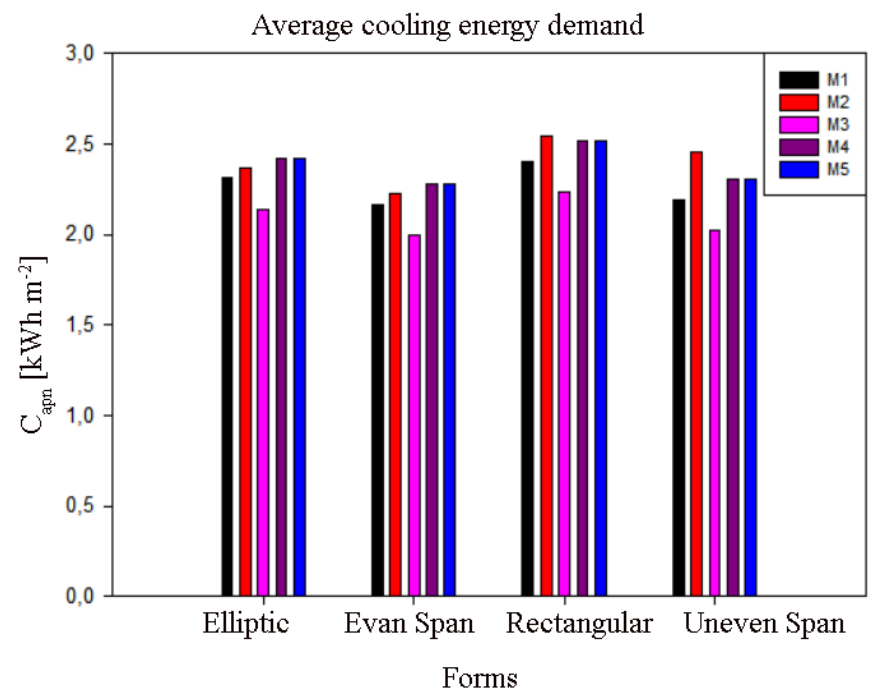

FIGURE 11. Cooling energy consumption $\left[\mathrm{kWh} \mathrm{m}^{-2}\right]$.

Figure 11 clearly shows that the Even span equipped within the covering material M03 had the lowest power requirement.

\section{Study of lighting needs of classic models:}

To determine the annual lighting consumption of the greenhouse, we simulated natural daylight to determine the conventional lighting fixture consumption through the use of daylight system controls.

\section{a) Daylight calculation}

In order to design the daylight system, we began by 3D modelling each shape of the selected greenhouse, and then defined the properties of the covering material, the type of reference sky (clear sky, global sky and overcast sky), and the hours and days considered for the simulation in 
order to create the natural light scenes. We simulated daylight from 07:00 to 22:00 and for days 1, 8, 15 and 22 of each month. This procedure was applied for all types and materials of greenhouse roofing. An example of daylight simulation of the elliptical shape equipped with M3 is shown in Figure 12 and Figure 13.

\section{Daylight Simulation results of August}

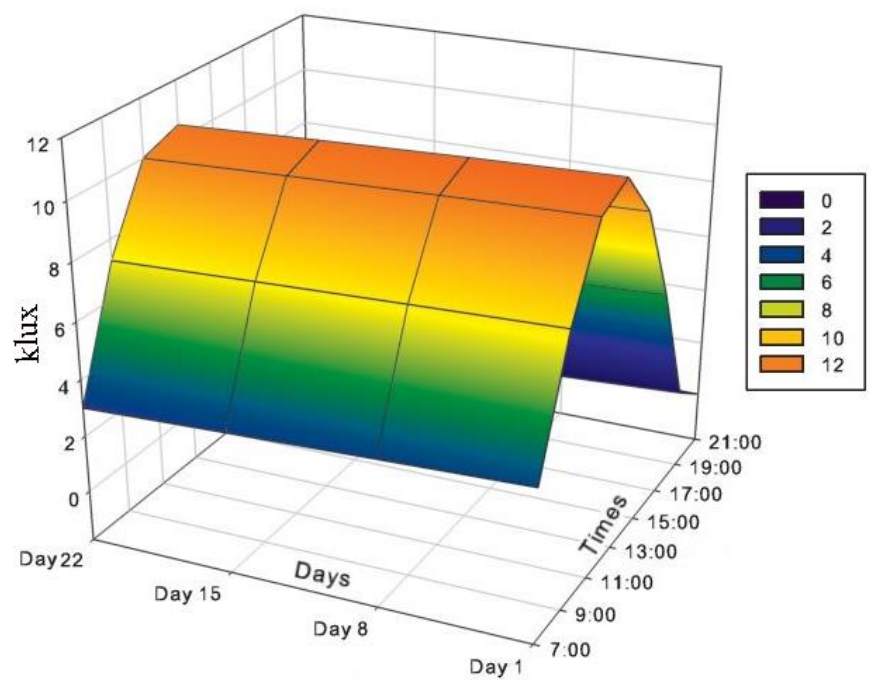

FIGURE 12. Results of the simulation of natural light in August [klux].

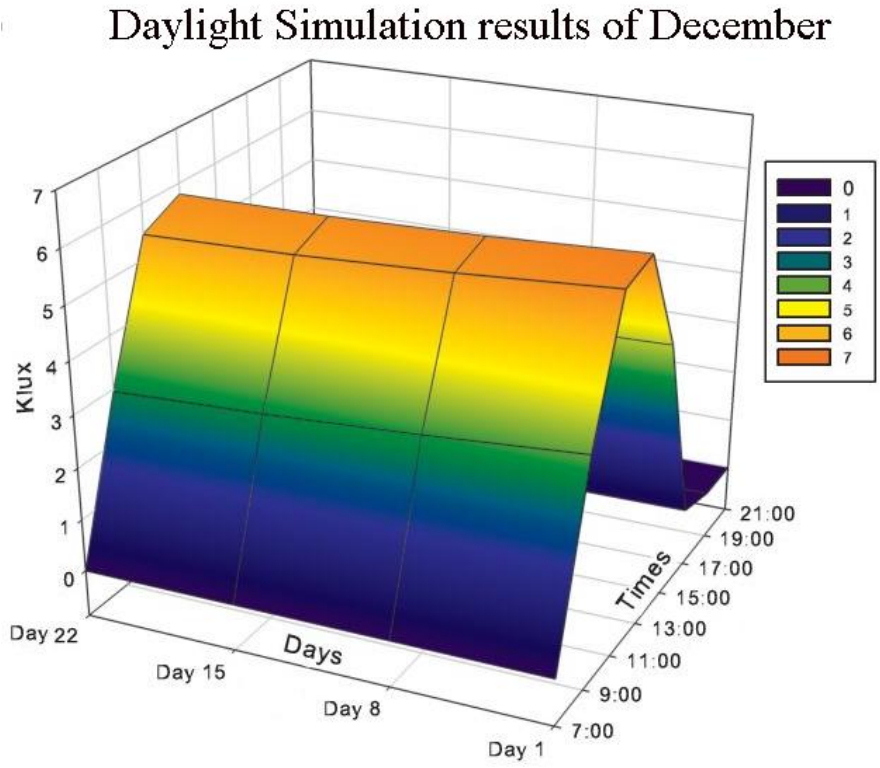

FIGURE 13. Results of the simulation of natural light in December [klux].

Figure 12 and Figure 13 describe the daylight results in the elliptical form equipped by M3 for the months of August and December.
In order to compare the daylight of the different shapes, we calculated the average daylight illuminance for each type of greenhouse used for the M3 cladding material, as shown in Figure 14. 
DAYLIGHT OF ALL TYPES OF THE GREENHOUSE

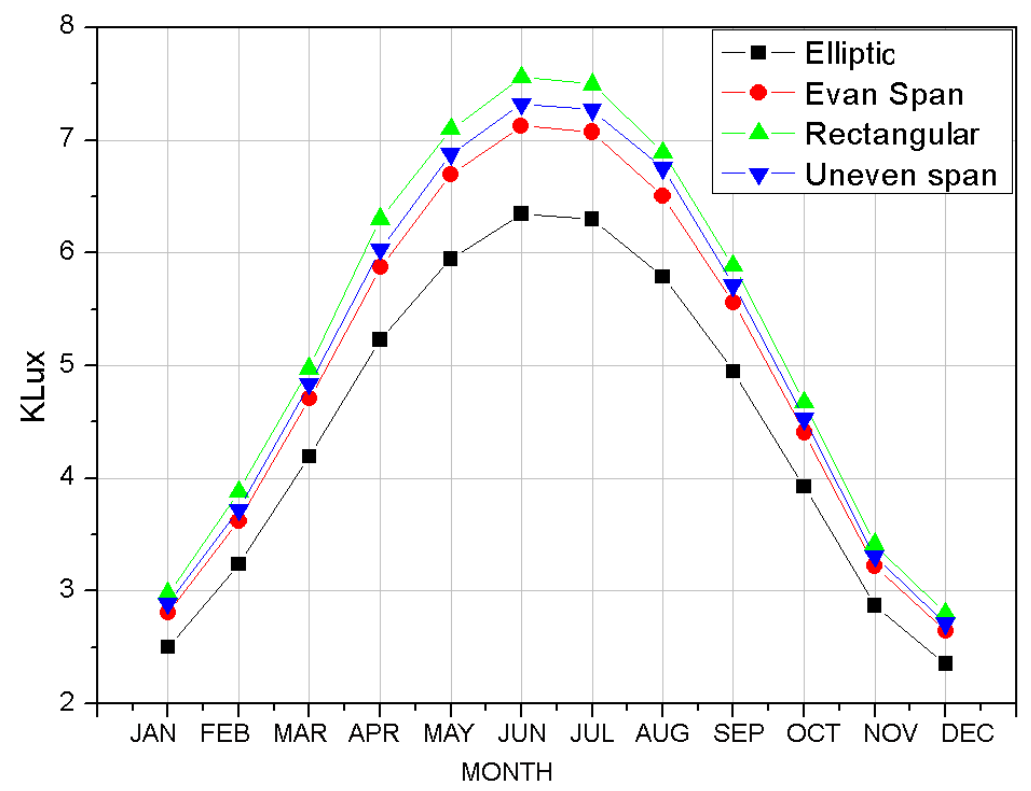

FIGURE 14. Daylighting in all types of greenhouse [klux].

Referring to Figure 14, it can be deduced that the rectangular shape of the greenhouse was, apparently, the best in terms of daylight and that the elliptical shape remains the least efficient.

In order to study the impact of cladding materials on daylighting, we simulated (through DIALUX EVO) all types of cladding materials for a reference date and time $(15 / 06 / 2018$ at 13:00), as lighting depends not only on transparency but also on reflection, light absorption, height, size and shape of the greenhouse. The results are presented in Table 4.

TABLE 4. Effect of roofing materials.

\begin{tabular}{ccc}
\hline Roofing materials & $\begin{array}{c}\text { Simulated illuminance on } \\
(\mathbf{1 5 - 0 6 - 2 0 1 8} \text { at 1 PM) [klux]. }\end{array}$ & $\begin{array}{c}\text { Light gain/loss compared to the M3 } \\
\text { reference in \%. }\end{array}$ \\
\hline M1 & 12.595 & Taken as a reference \\
\hline M2 & 13.331 & $-5.84 \%$ \\
\hline M3 & 11.715 & $6.99 \%$ \\
\hline M4 & 11.715 & $6.99 \%$ \\
\hline M5 & 13185 & $-4.68 \%$ \\
\hline
\end{tabular}

To combine the effect of the cladding material and the type of greenhouse, we applied the above gain/loss illuminance factor to all greenhouse types, as shown in Figure 15.

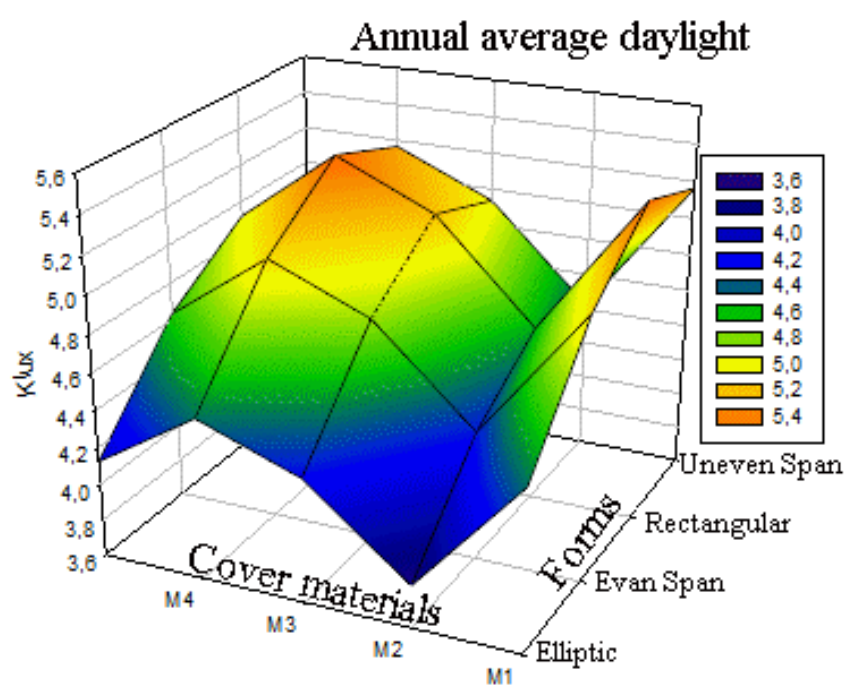

FIGURE 15. Average annual daylighting of all types of greenhouse [klux]. 
Figure 15 shows the daylight illumination of all types of greenhouse and it can clearly be seen that a rectangular greenhouse has the best value, in terms of Lux level, compared to the others. While M3 and M4 have the lowest illumination value, there is not much difference in the rest of the material.

\section{b) Energy demand for lighting}

In order to design the required artificial lighting, we applied the procedure described in Figure 16 to achieve the target brightness level of 8475 Lux [28] for tomato plants.

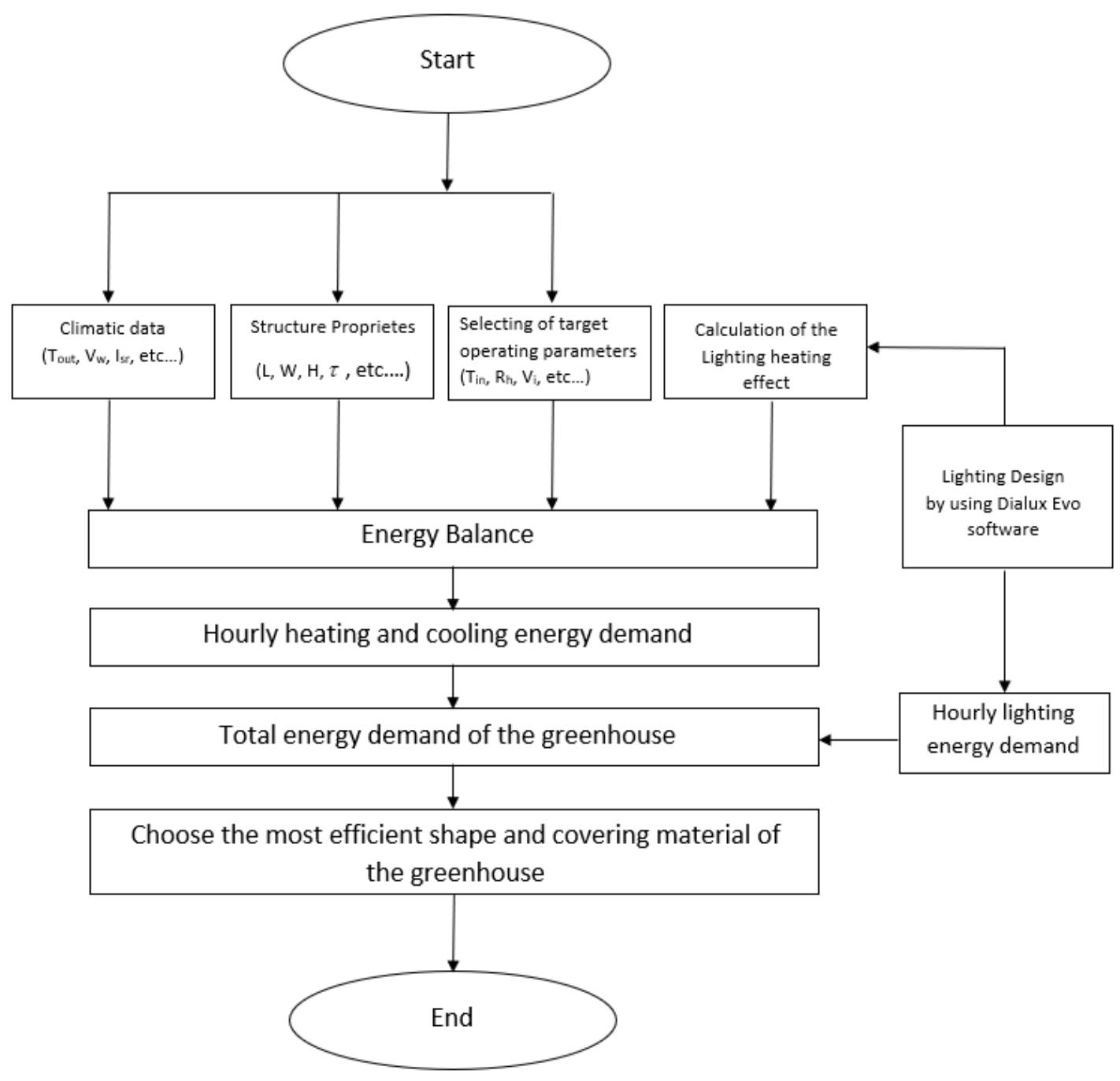

FIGURE 16. Lighting design process.

After all of the calculations were made, $140060 \mathrm{~W}$ light fixtures were suspended $1.8 \mathrm{~m}$ from the work surface (floor), with an output of $160 \mathrm{~lm} . \mathrm{W}^{-1}$ and a CCT of $4000 \mathrm{~K}$. According to the simulation, our objective was achieved with a lighting of 8478 Vs 8475 [lux] and a power consumption of approximately $60 \mathrm{~W} \cdot \mathrm{m}^{-2}$.

An example of the false colour rendering of the simulation is shown in Figure 17. 


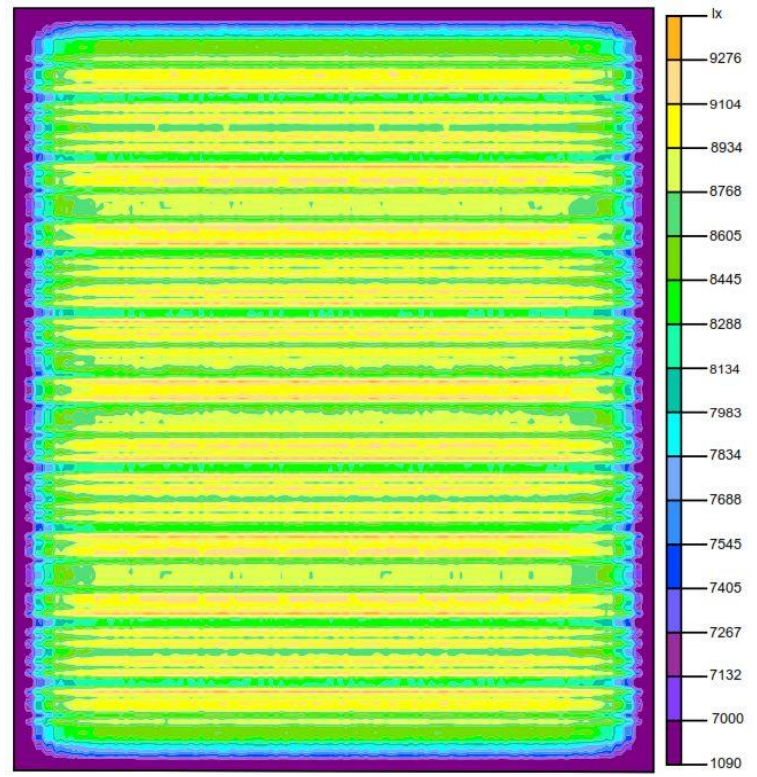

FIGURE 17. An example of false colour rendering of a lighting configuration and a light distribution map of the greenhouse [lux].

Figure 17 shows that the lighting was at the approximate target light level and that the light distribution remained uniform over the entire greenhouse surface.

To reduce light energy, we implemented a daylight control system. In order to synthesise the system, a light sensor was connected to a raspberry pi3 to transmit the value of the light in real time by converting the difference between the target value and the sensor value into a PWM signal. The brightness of luminaires has been modified in order to achieve the target lux level. This task was performed during the period [07:00 to 22:00] as long as the daily PPFD was lower than the target value of the tomato plant. When the daily PPFD was reached (between 7:00 to 22:00), the lighting was automatically switched off.

In order to estimate the average compensated illumination of all types of greenhouses equipped with M3 equipment, the illumination of the total number of installed lights (when all the lights are on) needed to be subtracted from daylight. Finally, we calculated the need for compensating lighting. In fact, we deduced the annual energy consumption of lighting for all types and materials of greenhouse roofing, see Figure 18.

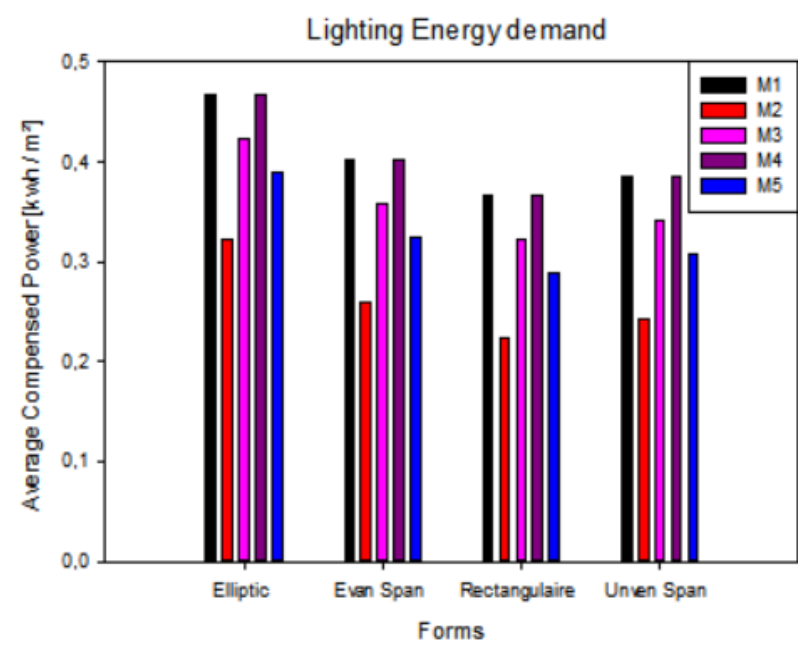

FIGURE 18. Energy demand for lighting in $\left[\mathrm{kWh} \mathrm{m}^{-2}\right]$.

We note that, in Figure 18, the need for energy compensation in lighting remains high compared to other forms of greenhouses, especially in the case of the rectangular shape.

\section{Global energy demand}

In order to calculate the overall energy consumption in the greenhouse, we summed the three compartments (heating, cooling and lighting) for the different forms and cover materials, as shown in Figure 19. 


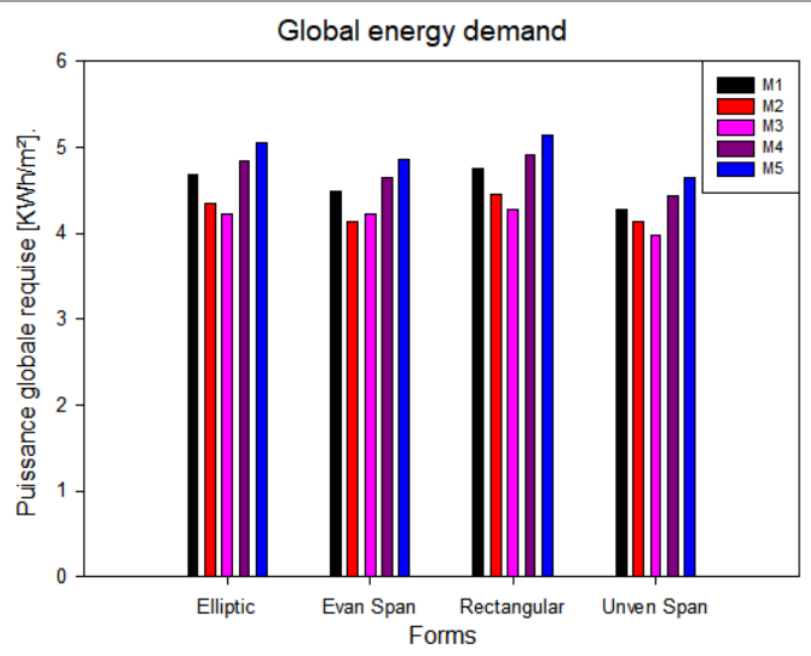

FIGURE 19. Global daily energy consumption [kWh m $\left.\mathrm{k}^{-2}\right]$.

Figure 19 clearly shows that the lowest overall energy consumption was recorded in the Uneven span greenhouse equipped with $\mathrm{M} 03$, while the rectangular shape equipped with M5 was the worst-case scenario, the latter could even cause us to lose more than $30 \%$ in electrical energy.

\section{Practical validation of the energy model}

In order to verify the performance of the designed 'BGHMC' model, we implemented an electric meter to compare the theoretical results with the measured results during the period from March 2019 to February 2020. The recorded results are shown in Figure 20.

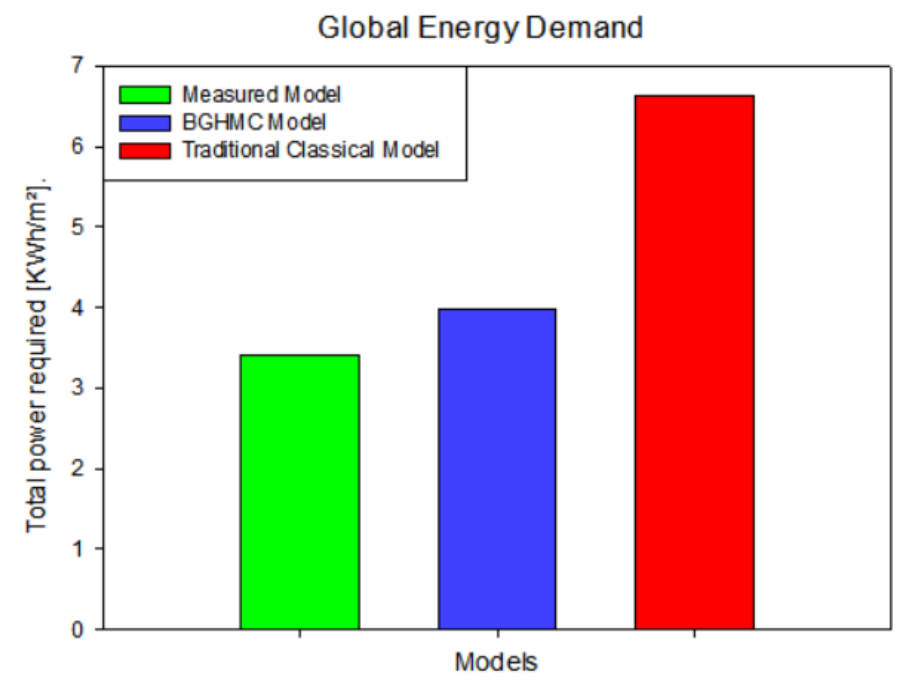

FIGURE 20. Global consumption of the different models [kWh m$\left.{ }^{-2}\right]$.

Figure 20 shows that the overall consumption of the BGHMC model was almost close to that recorded by the measured results, within a tolerance of about $12 \%$, while the energy estimate of the conventional model was totally wrong; it was more than double the effective consumption.

\section{RESULTS AND DISCUSSION}

Throughout this article, we have shown the importance of combining the three compartments (heating, cooling and lighting) in order to correctly estimate the electricity consumption in the greenhouse and then choose the most efficient form and covering material.

By limiting our work to the study of the heating system, we would have found that the most efficient form is the uneven span shape equipped with the M02 material whereas, in reality, the M03 material is the most efficient covering material. Such an error would have resulted in an over-consumption of $4.9 \%$.
By limiting our work to the study of the cooling system, we would have found that the most efficient form is the Even span shape equipped with the M03 material whereas, in reality, the Uneven span is the most efficient shape. Such an error would have resulted in an overconsumption of $5.5 \%$.

By limiting our work to the study of the lighting system, we would have found that the most efficient form is the rectangular shape equipped with the M02 material whereas, in reality, the Uneven span is the most efficient shape equipped with M03. Such an error would have resulted in an over-consumption of $11 \%$.

\section{CONCLUSIONS}

Throughout this research, we have shown that the energy consumption can only reveal its optimum values if all the main determinants, which have a direct effect on the fundamental process of greenhouse cultivation, are 
considered. The conclusions of this study are as follows:

- The energy consumption of a greenhouse could be optimised by adopting an uneven shape.

- The energy consumption could be improved significantly by using the appropriate M3 polyethylene as a greenhouse cover.

- The BGHMC model has proven to be accurate and reliable, compared to the traditional classical model; it has lead us to have a better accuracy $(51.48 \%)$ and a better error rate, compared to the actual measured consumption of $12 \%$.

Based on the above findings we can conclude that the best compromise between the choice of greenhouse shapes and covering materials, for efficient energy consumption, is essentially based on the calculation of the overall energy consumption, taking into account the consumption of heating, cooling and lighting.

\section{ACKNOWLEDGEMENTS}

I gratefully acknowledge the support and generosity of the BBL institute, without which the present study could not have been completed.

\section{REFERENCES}

Abbaspour-Gilandeh Y, Kaveh M, Jahanbakhshi A (2019) The effect of microwave and convective dryer with ultrasound pre-treatment on drying and quality properties of walnut kernel. Journal of Food Processing and Preservation 41(2): e12856. DOI:

https://doi.org/10.1111/jfpp.14178.

Abbaspour-Gilandeh Y, Jahanbakhshi A, Kaveh M (2020) Prediction kinetic, energy and exergy of quince under hot air dryer using ANNs and ANFIS. Food Science \& Nutrition 8(1): 594-611. DOI:

https://doi.org/10.1002/fsn3.1347.

Adedeji AA, Suhr E, Bhadriraju S, Alavi S (2017) Drying characteristics of bean analog - A sorghum based extruded product. Journal of Food Processing and Preservation. 41(2): e12856. DOI: https://doi.org/10.1111/jfpp.12856.

Adeli MM, Farahat S, Sarhaddi F (2020) Optimization of Energy Consumption in Net-Zero Energy Buildings with Increasing Thermal Comfort of Occupants. International Journal of Photoenergy: 1-17. DOI: https://doi.org/10.1155/2020/9682428

Ahemd HA, Al-Faraj AA, Abdel-Ghany AM (2016) Shading greenhouses to improve the microclimate, energy and water saving in hot regions: a review. Science Horticultural 201:36-45.

Aktas M, Sevik S, Amini A, Khanlari A (2016) Analysis of drying of melon in a solar-heat recovery assisted infrared dryer. Solar Energy. 137:500- 515. DOI: https://doi.org/10.1016/j.solener.2016.08.036.
Atalay H. Çoban MT, Kincay O (2017) Modeling of the drying process of apple slices: Application with a solar dryer and the thermal energy storage system. Energy. 134:382- 391. DOI: https://doi.org/10.1016/j.energy.2017.06.030.

Atia DM, El-Madany HT (2016) Analysis and design of greenhouse temperature control using adaptive neurofuzzy inference system. Journal of Electrical Systems and Information Technology 4(1): 34-48. DOI: https://doi.org/10.1016/j.jesit.2016.10.014

Aviara NA, Onuoha LN, Falola OE, Igbeka J (2017) Energy and exergy analyses of native cassava starch drying in a tray dryer. Energy. 73:809-817. DOI: https://doi.org/10.1016/j.energy.2014.06.087.

Belkadi A, Mezghani D, Mami A (2019) IoT and lighting control for smart greenhouse. Zenodo. DOI: http://doi.org/10.5281/zenodo.3813434.

Belkadi Anouar, Mezghani Dhafer, Mami Abdelkader (2020) Design and implementation of FLC applied to a smart greenhouse. Engenharia Agricola 40(6):777-790. DOI: https://doi.org/110.1590/1809-4430-

Eng.Agric.v40n6p777-790/2020.

Belkadi, Anouar, Mezghani Dhafer, Mami Abdelkader (2019) Energy design and optimization of a Greenhouse: a heating, cooling and lighting study. Engineering, Technology \& Applied Science Research 9(3):4235-4242. DOI: https://doi.org/10.48084/etasr.2787.

Chen ZM, Chen GQ (2011) An overview of energy consumption of the globalized world economy. Energy Policy 39(10): 5920-5928. DOI: https://doi.org/10.1016/j.enpol.2011.06.046.

Fan W, Hao Y (2019) An empirical research on the relationship amongst renewable energy consumption, economic growth and foreign direct investment in China. Renewable Energy. DOI: https://doi.org/10.1016/j.renene.2019.06.170.

Fitz-Rodriguez E, Kubota C, Giacomelli GA, Tignor ME, Wilson SB, McMahon M (2010) "Dynamic modeling and simulation of greenhouse environments under several scenarios: a web based application". Computers and Electronics in Agriculture 70(1): 105-116.

Ge Y, Bai G, Stoerger V, Schnable JC (2016) Temporal dynamics of maize plant growth, water use, and leaf water content using automated high throughput RGB and hyperspectral imaging. Computers and Electronics in Agriculture 127:625-632.

IRENA (2015) Renewable energy in the water, energy and food nexus. International Renewable Energy Agency 1-125.

Khattar N, Sidhu J, Singh J (2019) Toward energyefficient cloud computing: a survey of dynamic power management and heuristics-based optimization techniques. The Journal of Supercomputing. DOI: https://doi.org/10.1007/s11227-019-02764-2. 
Ma D, Carpenter N, Maki H, Rehman TU, Tuinstra MR, Jin J (2019) Greenhouse environment modeling and simulation for microclimate control. Computers and Electronics in Agriculture 162:134-142. DOI:

https://doi.org/10.1016/j.compag.2019.04.013.

Noorollahi Y, Bigdelou P, Pourfayaz F, Yousefi H (2016) Numerical modeling and economic analysis of a ground source heat pump for supplying energy for a greenhouse in Alborz province, Iran. Journal of Cleaner Production 131:145-154. DOI: https://doi.org/10.1016/j.jclepro.2016.05.059.
Wei H, Zhao J, Hu J, Jeong BR (2019) Effect of Supplementary Light Intensity on Quality of Grafted Tomato Seedlings and Expression of Two Photosynthetic Genes and Proteins. Agronomy 9(6):339. DOI: https://doi.org/10.3390/agronomy9060339.

Zhu J, Li D (2015) Current Situation of Energy Consumption and Energy Saving Analysis of Large Public Building. Procedia Engineering 121:1208-1214.DOI: https://doi.org/10.1016/j.proeng.2015.09.140. 